\title{
Hemoptysis Is a Critical Sign of Aortobronchial Fistula
}

\author{
Noriko Ashida-Urata, Tetsuya Nomura, Hajime Kamiya and Natsuya Keira
}

Key words: thoracic aortic aneurysm, aortobronchial fistula, hemoptysis

(Intern Med 56: 2683-2684, 2017)

(DOI: 10.2169/internalmedicine.8627-16)

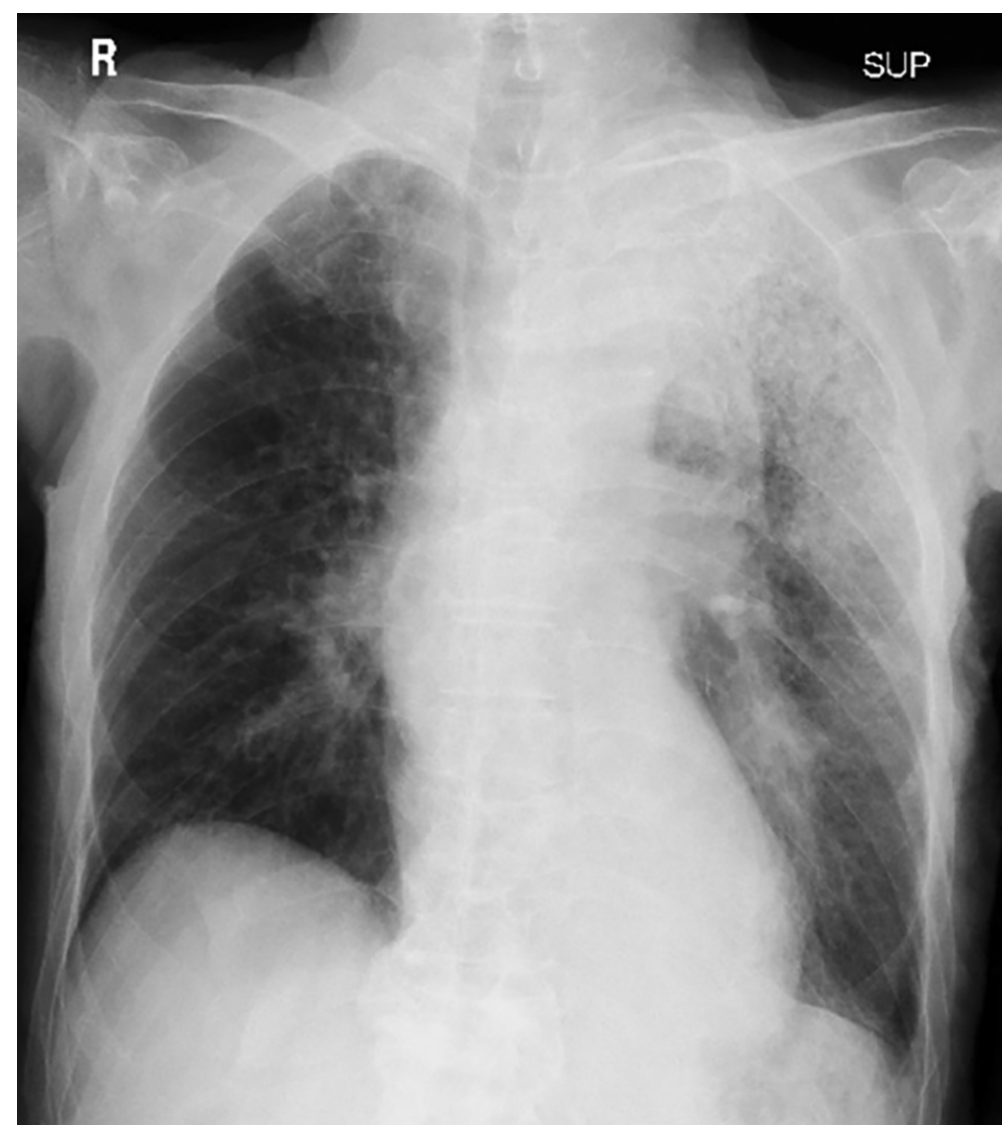

Picture 1.

An 89-year-old man complaining of hemoptysis was transferred to our emergency room. On arrival, his consciousness was clear and coarse crackle was auscultated in the left upper lung field. After chest computed tomography (CT), he suddenly developed cardiopulmonary arrest and could not be resuscitated. Chest X-ray revealed a positive silhouette sign at the thoracic aortic arch (Picture 1), and thoracic aortic aneurysm (TAA) was detected there by CT (Picture 2). A pathological autopsy showed that the TAA had ruptured through fibrous adhesions into the visceral pleura (Picture 3) and the bleeding spread through the lung parenchyma instead of the pleural space. (Picture 4). He was thought to have coughed up blood and choked to death. Aortobronchial fistula is an uncommon but highly lethal condition (1). Its early and accurate diagnosis, which depends on suspecting a disease condition at as early a stage as possible, is essential for adequate, life-saving treatment. Recently, thoracic endovascular aortic repair has been found to be a promising treatment for this highly lethal condition (2).

The authors state that they have no Conflict of Interest (COI). 

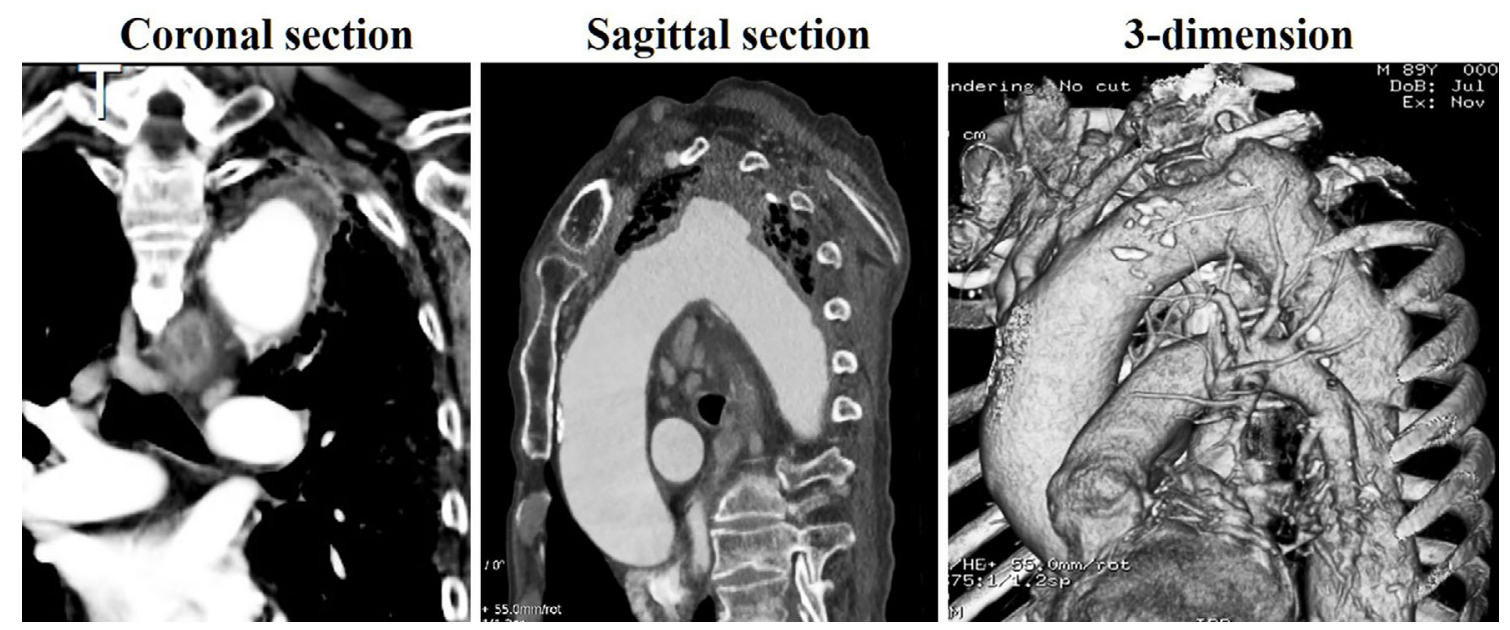

Picture 2.

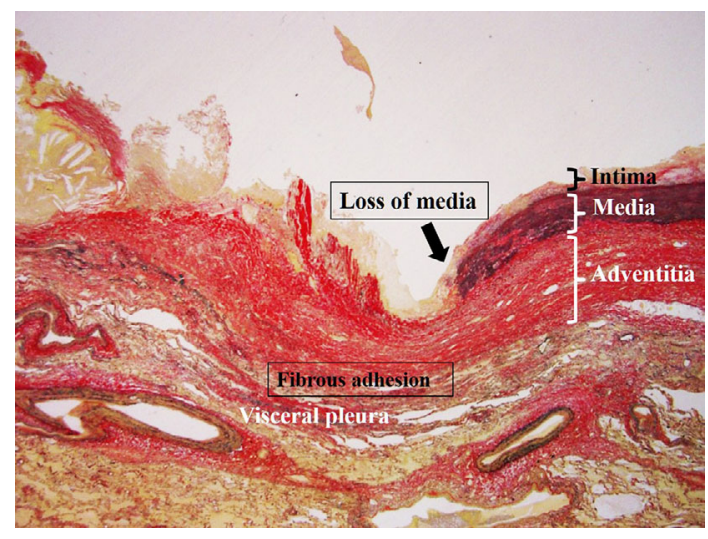

Picture 3.

\section{References}

1. Mosquera VX, Marini M, Pombo-Felipe F, et al. Predictors of outcome and different management of aortobronchial and aortoesophageal fistulas. J Thorac Cardiovasc Surg 148: 3020-3026, 2014.

2. Canaud L, Ozdemir BA, Bahia S, Hinchliffe R, Loftus I, Thompson M. Thoracic endovscular aortic repair for aortobronchial fistula. Ann Thorac Surg 96: 1117-1121, 2013.
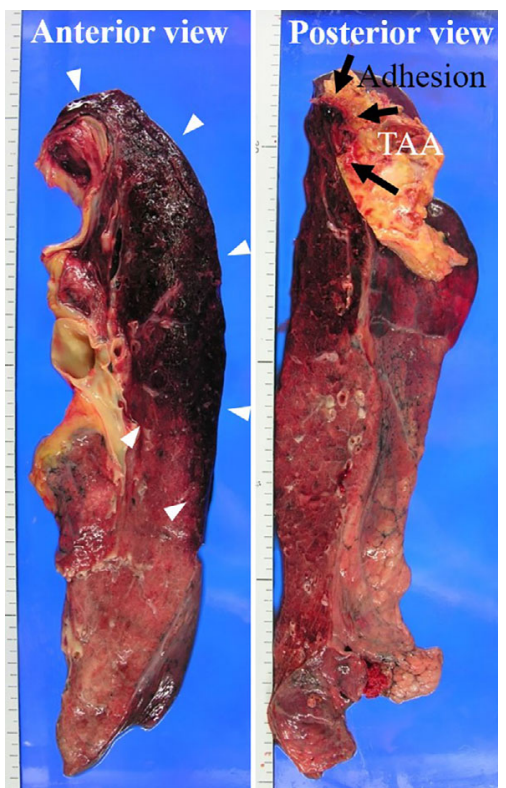

Picture 4.

The Internal Medicine is an Open Access article distributed under the Creative Commons Attribution-NonCommercial-NoDerivatives 4.0 International License. To view the details of this license, please visit (https://creativecommons.org/licenses/ by-nc-nd/4.0/).

(C) 2017 The Japanese Society of Internal Medicine Intern Med 56: 2683-2684, 2017 